\title{
Special Issue on the Alcohol Policy 16 Conference: Building Blocks for Sound Alcohol Policies, April 3-5, 2013, Washington, DC
}

\section{Editorial}

In 1981, the South Carolina Commission on Alcohol and Drug Abuse convened the first Alcohol Policy conference (AP1) in Charleston, to provide a forum where researchers, practitioners, and prevention advocates could discuss innovative policy approaches and research for preventing alcohol-related problems. Its director, Jerry McCord, used his position to organize AP1 to promote the careful consideration of alcohol policy issues from both a research and practitioner perspective at a time when few public officials were interested in pursuing alcohol control policies as a way to address-and reduce- - societal alcohol problems.

The intervening years have seen advances in the research and implementation of sound alcohol policies. Alcohol Policy 16: Building Blocks for Sound Alcohol Policies continued the series tradition by exploring progress in advancing evidence-based alcohol policies at the local, regional, national, and international levels. Experiences in alcohol policy research, development, implementation, enforcement, and evaluation at all four levels have acted as building blocks to identify and promote evidence-based strategies and to bring focus to the need for alcohol policy reform. Many alcohol control policies are embodied in laws and regulations at the federal, state, county, and city levels that affect how alcoholic beverages are manufactured, packaged, distributed, sold, and consumed. Research has demonstrated that such policies can alter dimensions of the environment that promote overall consumption as well as hazardous patterns of alcohol use, such as drinking and driving, within population groups.

AP16 drew approximately 270 researchers, policymakers, and community activities from 13 countries representing five continents to participate in 30 plenary and concurrent sessions and 39 poster sessions covering a wide range of topics, from global perspectives on the status of alcohol policy to juvenile curfew laws from a public health perspective. This special edition of the International Journal of Alcohol and Drug Research includes two commentaries and three papers illustrating the breadth of AP16's reach in identifying and promoting sound alcohol policy advancement across the world.

In his commentary "The Land of Insurmountable Opportunities,” Robert W. Denniston draws on his 36 years of experience working in various U.S. government agencies on public health and prevention issues to reflect on the progress and barriers affecting progressive alcohol policy development. In "Girls, Women, and Alcohol: Implications for Alcohol Policy," Ann Dowsett Johnston, a respected journalist with 35 years of experience in national media, comments on the importance of implementing evidence-based alcohol policies for addressing the rising tide of alcohol problems among women.

In "Engaging Youth in Alcohol Policy: The Lee Law Project," James Mosher and Maia D’Andrea evaluate a pilot program in Santa Cruz County to implement the law, which aims to limit youth exposure to alcohol advertising, reduce community blight, and promote public safety. Taisia Huckle, Li Chia Yeh, and Megan Pledger analyze the impact of lowering the minimum drinking age on alcoholrelated crashes in "Long-Term Effects of Lowering the Minimum Purchase Age for Alcohol in New Zealand." Ziming Xuan, Jason Blanchette, Toben Nelson, Timothy Heeren, Thien Nguyen, and Timothy Naimi report on their study "The Alcohol Policy Environment and Impaired Driving in U.S. States, and the Contribution of NonDriving Policies," which explored the association between the alcohol policy environment and self- reported impaired driving and tested the hypothesis that two policy environment subgroups-driving-oriented policies and drinking-oriented policies_are independently associated with impaired driving.

In addition to these papers, more than 25 conference presentations are posted on the Alcohol Policy 16 website at http://www.silvergategroup.com/ap16/agenda.html. To access these presentations, click on the sections in the agenda for poster and concurrent sessions, then scroll down to see the downloadable .pdf files associated with the session.

The U.S. Alcohol Policy Alliance is organizing Alcohol Policy 17, which is scheduled to take place on April 6-8, 2016, in Washington, DC. More details will be made available at http://alcoholpolicy.org/.

Barbara E. Ryan, Past President

Silver Gate Group 